\title{
A review on the status of natural orifice transluminal endoscopic surgery (NOTES) cholecystectomy: techniques and challenges
}

This article was published in the following Dove Press journal:

Open Access Surgery

9 September 2010

Number of times this article has been viewed

\author{
Michael C Meadows ${ }^{1,3}$ \\ Ronald S Chamberlain ${ }^{1,2,3}$ \\ 'Department of Surgery, Saint \\ Barnabas Medical Center, Livingston, \\ NJ, USA; ${ }^{2}$ Department of Surgery, \\ University of Medicine and Dentistry \\ of New Jersey, Newark, NJ, USA; \\ ${ }^{3}$ Saint George's University, School of \\ Medicine, West Indies, Grenada
}

Introduction: The evolution of techniques for the performance of a cholecystectomy over the last 25 years has been swift. The laparoscopic approach is now the gold standard for removal of the gall bladder and is the most frequently performed minimally invasive procedure globally. Currently in its infancy stage, natural orifice transluminal endoscopy surgery, or NOTES, is purported to be the next leap forward in minimally invasive approaches. The safety, feasibility, and effectiveness of this procedure, as well as the significance of potential benefits to patients beyond current surgical approaches are yet undetermined.

Methods: A comprehensive literature search was conducted using PubMed, a search engine created by the National Library of Medicine. Keywords used in the search included "natural orifice transluminal endoscopic surgery", "NOTES", "cholecystectomy", "transcolonic", "transvaginal”, and "transgastric". The accumulated literature was critically analyzed and reviewed.

Results: One-hundred and eighty-six cases of NOTES cholecystectomies have been published to date. Of these, 174 have been performed through a transvaginal approach. The remainder of the procedures were performed transgastrically. There are no published reports of transcolonic cholecystectomies performed in humans. Four of 186 cases $(2.15 \%)$ were converted to traditional laparoscopy due to intraoperative complications. No significant complications or mortalities have been reported.

Conclusion: NOTES cholecystectomy appears to be a feasible procedure. However, technical, safety, and ethical issues remain relatively unresolved. Besides improved cosmesis, whether additional patient benefits are likely to accrue, in comparison to traditional laparoscopic cholecystectomy or single incision laparoscopic surgery (SILS), is unclear. Development of instrumentation to facilitate novel NOTES techniques is in its infancy, but is critical if NOTES is to be broadly applicable. Larger human trials, the development of technological and educational platforms, and an open discussion regarding the ethical concerns are necessary if this approach is to move forward.

Keywords: natural orifice transluminal endoscopic surgery, NOTES, cholecystectomy, transvaginal, transgastric, transrectal, transcolonic

\section{Introduction}

Arguably the greatest surgical advancement in the latter half of the 20th century was the rapid adoption and propagation of laparoscopic surgery. Today, laparoscopic surgery is the gold standard for a vast array of surgical procedures and has resulted in decreased hospital time, postoperative pain, surgical site infections, adhesion formation, improved cosmesis, and a simpler and more rapid return to normal life. ${ }^{1}$ Over a similar time period, flexible endoscopy has also become well established in the diagnosis and treatment of both upper and lower gastrointestinal disorders.
Correspondence: Ronald S Chamberlain Saint Barnabas Medical Center, 94 Old Short Hills Rd, Livingston, New Jersey 07039, USA

Tel + I 9733225195

Fax + I $973322247 \mid$

Email rchamberlain@sbhcs.com 
Today, minimally invasive surgery stands on the verge of another giant advancement with the advent of natural orifice transluminal surgery (NOTES). Theoretically, NOTES combines minimally invasive surgical principles with flexible endoscopy and may ultimately permit some surgical procedures to be performed without skin incisions. NOTES aims to utilize the natural orifices of the body such as the mouth, anus, or vagina as the portal for entry into the peritoneal cavity. It is believed that the absence of abdominal wall incisions may allow NOTES approaches to further reduce abdominal pain, rates of infection, adhesion formation, ${ }^{2}$ and hernia formation among other benefits. ${ }^{3}$

Laparoscopy began in 1901 when German physician Georg Kelling first inserted a cystoscope into the peritoneal cavity of a dog and insufflated air to augment the view. ${ }^{4}$ In 1882, Carl Lagenbuch performed the first successful cholecystectomy on a 43-year-old man with symptomatic cholelithiasis. ${ }^{1}$ It took more than a century for these two sentinel surgical accomplishments to intersect, when in 1985 Eric Mühe performed the first laparoscopic cholecystecomy using a modified laparoscope called the galloscope. ${ }^{5}$ In 1987 , with the dawn of computer chip television cameras, Phillipe Mouret performed the first video-assisted laparoscopic cholecystectomy, ${ }^{6}$ and within five years, laparoscopic cholecystectomy became the gold standard for gallbladder removal and remains the most commonly performed laparoscopic procedure worldwide (see Table 1). ${ }^{7}$

In 2004, Kalloo et al published an innovative paper in which a transgastric peroral approach for entry into the peritoneal cavity was described. ${ }^{8}$ He performed this procedure on 17 porcine models, whereby a needle-knife puncture was made through the gastric wall and further widened by dilatation. A biopsy of the liver was performed followed by closure of the gastrotomy with clips. Since this initial report on the feasibility of NOTES in an animal model, there has been an increasing interest in the potential role of NOTES in humans.

Reddy and Rao were the first to successfully complete a NOTES procedure in a human subject when they performed a totally transgastric appendectomy in $2004 .^{9}$ The first transvaginal approach was performed by Marescaux et al in 2007, when they performed a transvaginal cholecystectomy on a 30 -year-old woman with symptomatic cholelithiasis. ${ }^{10}$

In July 2005, the Society of American Gastrointestinal Endoscopic Surgeons (SAGES) and the American Society for Gastrointestinal Endoscopy (ASGE) issued a joint paper designed to layout the technical challenges surrounding NOTES and to compile a set of guidelines aimed at the responsible development of NOTES platforms and technology. The group defined the technical challenges as (1) access to the peritoneal cavity, (2) safe gastric closure, (3) prevention of infection, (4) development of suturing devices, (5) development of anastomotic (nonsuturing) devices, (6) maintenance of spatial orientation, (7) development of a multitasking platform to accomplish procedures, (8) control of intraperitoneal hemorrhage, (9) management of iatrogenic intraperitoneal complications, (10) prevention of physiologic untoward events, (11) avoidance of compression syndromes, and (12) development of training platforms. ${ }^{11}$ The committee further recommended that all initial NOTES procedures be tested in animal models prior to human experimentation, stressed that appropriate IRB approval was a necessity and requested that all outcomes be recorded in a global registry and reported.

\section{Obstacles and challenges to the NOTES development}

As noted in the prior section, SAGES and the ASGE, as well as other organizations, have detailed the challenges involved with developing a broadly applicable NOTES platform. As a whole these obstacles can be grouped into three broad categories, which include patient access and closure, technological limitations, and ethical and training limitations.

\section{Patient access and closure}

NOTES is currently being investigated through three primary peritoneal access points: the vagina, stomach, and rectum. ${ }^{12}$ Safe access requires the ability to maintain a seal

Table I Surgical milestones in the transition from the first open cholecystectomy to the first NOTES cholecystectomy

\begin{tabular}{llll}
\hline Physician & Country & Year & Procedure \\
\hline Carl Lagenbuch & Germany & 1882 & First open cholecystectomy \\
Georg Kelling & Germany & 1901 & First laparoscopic view of the peritoneal cavity with insufflation in a dog \\
Erich Mühe & Germany & 1985 & First laparoscopic cholecystectomy \\
Phillipe Mouret & France & 1987 & First video-assisted laparoscopic cholecystectomy \\
Kalloo et al & India & 2004 & First published description of NOTES \\
Reddy et al & India & 2004 & First human NOTES procedure (appendectomy) \\
Marescaux et al & France & First "hybrid” transvaginal human NOTES cholecystectomy \\
Gumbs et al & USA & 2007 & First transvaginal "pure” NOTES cholecystectomy
\end{tabular}


and manipulate the instrument, the provision of adequate and stable exposure, and the avoidance of significant trauma or injury. ${ }^{13}$ Among the three proposed peritoneal access sites, the transvaginal route offers the smallest learning curve due to extensive transvaginal experience in gynecological surgeries, the ability to use rigid instrumentation with optical correctness and the availability of reliable closure devices to safely close the colpotomy. These factors help explain why the transvaginal route of access currently accounts for $93.5 \%$ of all NOTES procedure performed to date.

While gaining peritoneal access through the stomach ${ }^{9}$ or rectum $^{2,14}$ is feasible, reliable closure devices are not readily available to the NOTES surgeon. Natural concerns centering on risk of postoperative leak and peritoneal contamination via transgastric and transcolonic NOTES approaches has also slowed human experimentation; however several prototypes for safe access and gastric closure have been developed (see Table 2). ${ }^{15}$ Many of these devices have produced favorable outcomes in in vivo porcine models; however there has been limited data to support human clinical use. In fact, while each device may have its special advantages and disadvantages, no data comparing the efficiency, safety, or the reliability of these prototypes exists.

Voermans et al evaluated seven different gastrotomy closure devices in an ex vivo model, which involved filling the stomach with air and assessing burst pressures. ${ }^{16}$ All closures were done manually to guarantee an ideal seal. These authors reported that the burst pressures for the Eagle Claw VIII, the flexible stapler and the flexible Endostitch closures were equivalent to hand-sewn interrupted surgical suture closure with 3.0 polydioxane II (206 $\mathrm{mmHg}$ ). Purse string modified $\mathrm{T}$ tags, purse string suturing devices and the $\mathrm{T}$ tags were

Table 2 Gastric and intestinal closure devices currently being tested for transgastric and transcolonic NOTES ${ }^{16}$

\begin{tabular}{|c|c|c|c|}
\hline Closure device & Description & Advantage & Disadvantage \\
\hline $\begin{array}{l}\text { T tags (Ethicon Endo-Surgery, Cincinnati, } \\
\text { OH, USA) }\end{array}$ & $\begin{array}{l}\text { Metal "T"-bar and thread loaded } \\
\text { onto a I9-gauge hollow needle } \\
\text { passed through tissue lateral of } \\
\text { defect and anchor is ejected beyond } \\
\text { wall. Another anchor is placed in } \\
\text { the same manner on the opposite } \\
\text { side of defect and the tissue is } \\
\text { approximated by a locking cinch. }\end{array}$ & Strength & $\begin{array}{l}\text { Leaks through needle holes, due } \\
\text { to excessive apposition force } \\
\text { between anchors. Blind } \\
\text { punctures through gastric wall. }\end{array}$ \\
\hline $\begin{array}{l}\text { Purse string modified T tags } \\
\text { (Cook Endoscopy, Winston- } \\
\text { Salem, NC, USA) }\end{array}$ & $\begin{array}{l}\text { A metal ring is added to the } \\
\text { midpoint to the tradition } T \text { tag } \\
\text { device in order to deploy four } \\
\text { sutures sequentially, in a square } \\
\text { pattern, on the same suture. }\end{array}$ & $\begin{array}{l}\text { Allows } 4 \text { fasteners to be } \\
\text { sequentially deployed } \\
\text { on same suture }\end{array}$ & Strength \\
\hline $\begin{array}{l}\text { Purse string suturing device } \\
\text { (LSI Solutions, Victor, NY, USA) }\end{array}$ & $\begin{array}{l}\text { Creates a vacuum to draw the } \\
\text { gastric wall into a chamber in } \\
\text { which a 3-mm blade may make } \\
\text { an incision. Sutures are deployed } \\
\text { and tightened with a titanium knot. }\end{array}$ & $\begin{array}{l}\text { Easy to use, rapid and } \\
\text { adequate closure, negates } \\
\text { endoscopic knot tying }\end{array}$ & Tissue tear at clip site \\
\hline $\begin{array}{l}\text { Flexible stapler (Power Medical } \\
\text { Interventions, Langhorne, PA, USA) }\end{array}$ & $\begin{array}{l}\text { Computer-guided cutting and } \\
\text { stapling device on a flexible shaft. }\end{array}$ & $\begin{array}{l}\text { Easy to use, rapid and } \\
\text { adequate closure, negates } \\
\text { endoscopic knot tying }\end{array}$ & Size and maneuverability in vivo \\
\hline $\begin{array}{l}\text { Flexible Endostitch (Covidien, } \\
\text { North Haven, CT, USA) }\end{array}$ & $\begin{array}{l}\text { Opening and closing of the jaws } \\
\text { moves a needle to opposite sides } \\
\text { and through the tissue. Barbs keep } \\
\text { the suture secure to the tissue } \\
\text { without the need to endoscopically } \\
\text { tie a knot. }\end{array}$ & $\begin{array}{l}\text { Easy to use, rapid and } \\
\text { adequate closure, negates } \\
\text { endoscopic knot tying }\end{array}$ & Size and maneuverability in vivo \\
\hline $\begin{array}{l}\text { Resolution clips (Boston } \\
\text { Scientific, Natick, MA, USA) }\end{array}$ & Standard endoclips & Ease of use & $\begin{array}{l}\text { Incomplete closure (Deep } \\
\text { layers may slip from clip) }\end{array}$ \\
\hline $\begin{array}{l}\text { Eagle Claw VIII (Olympus } \\
\text { Corporation, Tokyo, Japan) }\end{array}$ & $\begin{array}{l}\text { Attached to the tip of the } \\
\text { endoscope, opposing jaws can } \\
\text { move simultaneously, one jaw } \\
\text { attaches to the tissue, while the } \\
\text { other jaw holds a curved needle } \\
\text { to deliver a suture through the } \\
\text { tissue. The needle tip can detach } \\
\text { and lock into the suture device } \\
\text { cartridge once jaws are locked. }\end{array}$ & Ease of use & Still in prototype phase \\
\hline
\end{tabular}


inferior to hand-sewn closure in regards to burst pressure. Since no endoscopic instrumentation was used to close the defects in this study, this data does not necessarily reflect the quality of the seal and burst pressures that may be achievable during in vivo NOTES procedures. In vivo studies and additional ex vivo analysis are vital to more fully understand the advantages and disadvantages of each device.

A major concern facing transgastric NOTES development and transrectal approaches centers on the issue of peritoneal contamination and the potential development of intra-abdominal infection. Lomanto et al compared the risk of peritoneal contamination after a transvaginal versus a transgastric NOTES approach. ${ }^{12}$ These authors administered preoperative intravenous antibiotics (cephazolin, $1 \mathrm{~g}$ ) followed by povidone-iodine/saline lavage to either the stomach or vagina in a porcine animal model. A transgastric left tubal ligation or a transvaginal cholecystectomy was then performed. Peritoneal cultures were obtained immediately after entry into the abdomen, at the end of the procedure, and at euthanasia. Three of six $(50 \%)$ animals in the transgastric group developed signs of postoperative peritonitis with evidence of peritoneal abscesses and isolation of E. coli at autopsy; whereas no infections were noted in the transvaginal cholecystectomy group.

In a study designed to assess the need for decontamination of the stomach prior to gastrotomy, Narula et al performed diagnostic transgastric peritoneoscopy on 10 patients. ${ }^{17}$ Thirty minutes prior to the procedure, patients received a preoperative dose of prophylactic antibiotics (cephazolin, $1 \mathrm{~g}$ ). A gastric lavage with povidone-iodine/saline solution was not performed. Intragastric and peritoneal samplings were obtained before and after creation of the gastrotomy including qualitative and quantitative microbiological cultures. No infectious complications were reported in any patient. The authors concluded that although transgastric instrumentation may result in contamination of the abdominal cavity $(642.1 \mathrm{CFU} / \mathrm{mL}$ post-gastrotomy versus $132.1 \mathrm{CFU} / \mathrm{mL}$ pre-gastrotomy), quantitatively the number of pathogens was below the threshold necessary to result in a clinically significant infection and no cross-contamination between the intragastric bacterial species and peritoneal species was noted.

It should be noted that transvesical NOTES approach to the peritoneal cavity has had an initial enthusiastic phase. ${ }^{18}$ In 2007, Rolanda et al performed an exclusively "pure" natural orifice cholecystectomy on 7 porcine models through a combined transgastric and transvesical approach. ${ }^{19}$ The transvesical port allowed for visualization of the gastrotomy and the utilization of rigid instrumentation for retraction of the gallbladder. The dissection, clipping and sectioning of the cystic duct and artery and removal of the gallbladder were done entirely through the gastrotomy port. Although 5 of the $7(71.4 \%)$ porcine cholecystectomies were completed without complication, no further investigations of this approach for cholecystectomies have been published. Cindolo and his urologist team summarized that transvesical NOTES seem likely to flourish only in specific urological conditions, if at all. ${ }^{18}$

\section{Technological limitations: exposure, flexibility, and retroflexion}

Flexible endoscopy is the only platform currently available to obtain peroral transgastric access to the peritoneum. ${ }^{20}$ In general, flexible endoscopes are designed for diagnostic and therapeutic procedures inside the gastrointestinal tract lumen rather than the open space of the peritoneal cavity. Spatial orientation, retroflexion instability of the instrument, and small instrument channels pose major challenges yet to be overcome. ${ }^{21-24}$ Specifically, visualization of the gallbladder in the right upper quadrant requires the scope to be retroflexed, which significantly limits the rigidity of instruments that can be used and developed for transgastric surgery. ${ }^{25}$ This lack of rigidity severely limits the counter forces down the shaft which can be applied to adequately retract tissue and apply strong sutures or clips., ${ }^{2,26}$ Several attempts to develop rigid or semirigid platforms to overcome this limitation are currently being explored. Swanstrom and described a novel shape-locking overtube that stabilizes the endoscope while in a retroflexed position. ${ }^{27}$ This $18-\mathrm{mm}$ overtube (USGI Medical, San Clemente, CA, USA) has multiple channels which allow a camera and two instruments with up to $5.5-\mathrm{mm}$ diameter to be used. Additional smaller channels are also present to permit insufflation and irrigation. As expected, results with these early devices were not ideal, and only one of three (33.3\%) attempted porcine model NOTES cholecystectomies were completed successfully. ${ }^{26}$ Sumiyama and Gostout described a submucosal endoscopy with mucosal flap (SEMF) technique for peritoneal access. ${ }^{28}$ This is carried out by creating a submucosal bleb formed by the injection of $\mathrm{CO} 2$ into this layer. A needle knife incision is made at the margin of this bleb. On the opposite side of this incision and within the submucosal space, an endoscope with an attached endoscopic mucosal resection cap is inserted to resect the muscular layer to gain access to the peritoneal cavity. This flap-creating technique has advantages of safer access by avoiding injury to surrounding structures, and allows for easy maintenance of gastric distension throughout the procedure. By creating 
a "submucosal tunnel" to the upper quadrant and utilization of a multibending endoscope, these authors were able to successfully perform transgastric NOTES cholecystectomies in four porcine models.

In addition to lack of rigidity, flexible endoscopic shafts also limit the force that can be applied to retract tissue. A variety of methods to provide retraction of the gallbladder using transabdominal stay sutures, clips or magnets that can be manipulated through the skin have been reported. ${ }^{29-31}$ Ryou and Thompson utilized an external magnetic assembly clamped to the edge of the operating table which was able to retract tissue after internal magnets were attached to the tissue using endoscopic clips. ${ }^{29}$ The clips were deployed in serial fashion along the inferior edge of the hepatic lobes in order to lift the hepatic lobes and expose the gallbladder. Despite minor trauma to the liver, the gallbladder was fully exposed in four of the five porcine models studied. The procedure time was shortened by $27 \%$ when magnets were used. Note, thicker abdominal walls or manipulation of targets more centrally located in the peritoneal cavity would require extremely powerful magnetic systems and patients with pacemakers, metal foreign bodies or recently implanted metal orthopedic prostheses may pose a potential contraindication.

As with all new technology in its infancy, most NOTES platforms are prototypes and suboptimal. Consensus as to whether the "ideal" NOTES platform will be a flexible endoscope alone, a multilumen overtube, a complex robotic system or a combination of these remains unknown.

Karimyan et al reviewed 5 separate navigational platforms, including 3 robotic systems, which are currently being developed for NOTES procedures. ${ }^{32}$ These authors evaluated the devices based on size, image quality, insufflation ease, suction/irrigation ease, maneuverability, stability, and ability to provide triangulation. They found no system uniquely superior to all others and surmised that significant improvements were needed. These authors also stressed that once an "ideal" platform for NOTES is available, and it may not be just one, an ongoing "give and take" between surgeons and engineers is necessary to further mature this new technology.

\section{Ethical and training challenges of NOTES}

Before "incisionless" surgery, that is NOTES, becomes rapidly adopted, a robust discussion concerning the ethics of NOTES must ensue. Although the transvaginal route is currently deemed a safe approach for avoiding iatrogenic injury, no studies have evaluated the potential for future fertility issues, dyspareunia, vaginal cuff dehiscence, or bowel herniation. ${ }^{7,33}$ Lacking this important information, it is imperative that the informed consent process, as with all investigational procedures, be comprehensive, honest, and robust. Given our present inability to point to any significant clinical advantages to NOTES over traditional laparoscopic surgery or SILS, an on-going open discussion regarding the ethics of NOTES should proceed in parallel with its development.

Whether NOTES becomes a mainstream surgical procedure or is limited to select centers is unclear. Given the current limitations, and the limited number of general surgeons well-trained in flexible endoscopy, broad applicability of NOTES seems unlikely except in the case of transvaginal approaches for select women. Once a reliable NOTES platform exists, extensive efforts at training and reeducation will be necessary if this procedure is to be safely performed. Given the perceived steep learning curve for the average general surgeon possessing limited flexible endoscopy credibility, virtual reality, and computer-based systems with immediate feedback and performance analysis will be necessary to develop a proficient simulator and permit credibility for this technology. ${ }^{34}$ Moreover, NOTES will ultimately expand the field of general surgery, gastroenterology or result in a new "hybrid" specialty is as of yet unclear.

\section{Patient selection criteria for NOTES}

If we are to develop NOTES technology safely it must proceed in a gradual fashion. As such, these procedures should be limited to "ideal candidates" who pose low procedural complication risks. While no comprehensive patient selection criteria has been published to date, most investigators have selected patients for NOTES cholecystectomy who are: (1) thin (BMI < 35), (2) have no evidence of acute cholecystitis, (3) have had no prior abdominal or pelvic surgeries, and (4) who have no history or current symptoms of endometriosis or pelvic inflammatory disease. ${ }^{33,35}$ When you also consider the fact that $>90 \%$ of all published NOTES cholecystectomy have been performed via the transvaginal route, and that women who have had endometriosis, cesarean section, pelvic/vaginal or abdominal surgery, or pelvic inflammatory disease are excluded, the size of the potential NOTES cholecystectomy candidate pool seems quite small. Although patient selection criteria for NOTES will certainly become less stringent with experience, it will no doubt remain a procedure for a small number of informed patients rather than for the general population. Although, some have advocated that sicker patients who are not suitable for laparoscopic 
surgery (intensive care patients) may have NOTES performed as a bedside procedure in the future, this seems fanciful and would be limited to diagnostic NOTES peritoneoscopy rather than a therapeutic procedure. ${ }^{36}$

\section{Patient acceptance of NOTES approaches to cholecystectomy}

Although physicians and surgeons are intrigued by the notion of "incisionless" surgery, whether patients will consent to these investigational procedures is not certain. Among 100 patients questioned on their feeling about NOTES, $78 \%$ stated that they would prefer NOTES to a traditional laparoscopic cholecystectomy. ${ }^{37}$ The most common reason for preferring NOTES was to avoid incisional pain and scarring, however the extent of post-procedural pain has yet to be quantified in a NOTES study comparing it to traditional laparoscopic cholecystectomy. Over $97 \%$ of the patients surveyed stated that they would consent to a NOTES approach only if the risk of complications were equal to or lower than a laparoscopic approach. Interestingly, both men (92\%) and women $(87 \%)$ preferred an oral route of access over transvaginal and transrectal approaches. Eighty-two percent of the surveyed group who preferred laparoscopic cholecystectomy over NOTES stated that they considered the complication risks and the proven safety and efficacy of the procedure the most important factors in selecting this procedure. When the complication rates of NOTES were described to the entire group as potentially higher than a traditional laparoscopic cholecystectomy, overall interest decreased to less than $15 \%$.

\section{Transitioning to NOTES: the "hybrid" NOTES and SILS approaches}

While awaiting engineering and technical solutions to many challenges surrounding NOTES, many surgeons have developed "hybrid" techniques in an effort to transition us towards "incisionless" surgery. "Hybrid" NOTES involves making one or several incision(s) on the abdominal wall and inserting a trocar(s) for aid in overcoming current barriers such as permitting the use of rigid laparoscopic instrumentation for retraction of surrounding tissue and direct visualization of the transluminal incision. A large number of "hybrid" techniques have been described which involve placement of needles or ports through the abdominal wall for a variety of reasons including: (1) gaining optic connection, (2) use of rigid instrumentation, (3) stable retraction, (4) visualization of the colpotomy or gastrotomy, and (5) safe closure of organ incision. ${ }^{10,35,38-48}$ These approaches are detailed in Table 3. Echoing comments by many, Zornig et al have rhetorically asked whether these hybrid techniques should be termed "laparoscopically assisted transvaginal surgery" or "transvaginally assisted laparoscopic surgery" rather than "hybrid" NOTES. ${ }^{35}$

Parallel to the development of NOTES, has been the emergence of single incision laparoscopic surgery or SILS, as a means to bridge the current technological gap between standard laparoscopy and NOTES. A variety of procedures has been described which involve a single umbilical skin incision followed by insertion of a 3- or 4-port trocar or placement of multiple trocars through the same SILS incision. ${ }^{7}$ Navarra et al reported the first SILS cholecystectomy in 1997 using two $10-\mathrm{mm}$ trocars and three transabdominal stay sutures to facilitate gallbladder retraction. ${ }^{49}$ A substantial number of human trials and large case reports have emerged to confirm the feasibility and safety of SILS (see Table 4). ${ }^{31,49-61}$ However, as with NOTES, whether SILS provides for any non-cosmetic advantages versus traditional laparoscopic cholecystectomy is unclear. Moreover, whether SILS will result in increased risk of hernia and wound complications is also an unanswered concern.

The remainder of this review will focus on published reports of human NOTES cholecystectomy. "Hybrid" NOTES procedures will be defined as any NOTES procedure that involves transabdominal needles or laparoscopic instruments, whereas procedures done entirely with only transluminally placed instrumentation will be referred to as a "pure" NOTES procedure.

\section{Published reports of human NOTES cholecystectomy Transvaginal approach to NOTES cholecystectomy}

One hundred and seventy-four of the 186 (93.5\%) NOTES cholecystectomies reported in humans have been performed via a transvaginal route. In general, the ability to use current rigid instrumentation and familiarity with transvaginal surgery for performing other procedures such as hysterectomies has provided a "comfort level" for more rapid maturation of this access method. In a recent survey of 181 Chairmen of Obstetrics and Gynecology, $69 \%$ reported that the transvaginal approach was an ethical and sound approach for the advancement of NOTES, while only $31 \%$ considered it experimental. ${ }^{33,62}$ In addition, 
Table 3 All published reports of transvaginal "hybrid" NOTES cholecystectomy

\begin{tabular}{|c|c|c|c|c|c|}
\hline Authors & Peritoneal access & Number of incisions & Size of trocars & Location of trocars & Purpose \\
\hline $\begin{array}{l}\text { Marescaux et al } \\
(2007)^{10}\end{array}$ & Transvaginal & 0 & 2-mm needle port & Right hypochodrium & $\begin{array}{l}\text { Insufflation, laparoscopic } \\
\text { visualization, and retraction }\end{array}$ \\
\hline $\begin{array}{l}\text { Branco Filho et al } \\
(2007)^{47}\end{array}$ & Transvaginal & 1 & $5-\mathrm{mm}$ & Umbilicus & $\begin{array}{l}\text { Maintain insufflation, } \\
\text { mobilization of gallbladder }\end{array}$ \\
\hline $\begin{array}{l}\text { Zornig et al } \\
(2007)^{41}\end{array}$ & Transvaginal & 1 & $5-\mathrm{mm}$ & Umbilicus & $\begin{array}{l}\text { Insufflation, laparoscopic } \\
\text { visualization, additional } \\
\text { dissection port using rigid } \\
\text { instrumentation, mobilization } \\
\text { of gallbladder }\end{array}$ \\
\hline $\begin{array}{l}\text { Zornig et al } \\
(2009)^{35}\end{array}$ & Transvaginal & 1 & $5-\mathrm{mm}$ & Umbilicus & $\begin{array}{l}\text { Insufflation, laparoscopic } \\
\text { visualization, additional } \\
\text { dissection port using rigid } \\
\text { instrumentation }\end{array}$ \\
\hline $\begin{array}{l}\text { Navarra et al } \\
(2009)^{38}\end{array}$ & Transvaginal & 1 & $5-\mathrm{mm}$ & Umbilicus & $\begin{array}{l}\text { Insufflation, laparoscopic } \\
\text { visualization, retraction, } \\
\text { primary port for dissection } \\
\text { using rigid instrumentation }\end{array}$ \\
\hline $\begin{array}{l}\text { Palanivelu et al } \\
(2009)^{43}\end{array}$ & Transvaginal & 1 & $3-\mathrm{mm}$ & Umbilicus & $\begin{array}{l}\text { Laparoscopic visualization, } \\
\text { retraction }\end{array}$ \\
\hline $\begin{array}{l}\text { Zorrón et al } \\
(2007)^{40}\end{array}$ & Transvaginal & 1 & $3-\mathrm{mm}$ & Right hypochodrium & Retraction \\
\hline $\begin{array}{l}\text { Zorrón et al } \\
(2008)^{39}\end{array}$ & Transvaginal & 1 & 2- or 3-mm & Right hypochodrium & Retraction \\
\hline $\begin{array}{l}\text { Forgione et al } \\
(2008)^{42}\end{array}$ & Transvaginal & 1 & $3-\mathrm{mm}^{\mathrm{b}}$ & Left upper quadrant & $\begin{array}{l}\text { Laparoscopic visualization, } \\
\text { insufflation }\end{array}$ \\
\hline $\begin{array}{l}\text { Ramos et al } \\
(2008)^{48}\end{array}$ & Transvaginal & 2 & $5-\mathrm{mm}$ and $2-\mathrm{mm}$ & $\begin{array}{l}\text { Umbilicus and right } \\
\text { hypochodrium, } \\
\text { respectively }\end{array}$ & $\begin{array}{l}\text { 5-mm: laparoscopic } \\
\text { visualization, primary port } \\
\text { for dissection and clipping } \\
\text { 2-mm: retraction }\end{array}$ \\
\hline $\begin{array}{l}\text { Noguera et al } \\
(2009)^{46}\end{array}$ & Transvaginal & 2 & $5-\mathrm{mm}$ and 3-mm & $\begin{array}{l}\text { Umbilicus and right } \\
\text { upper quadrant, } \\
\text { respectively }\end{array}$ & $\begin{array}{l}\text { 5-mm: laparoscopic } \\
\text { visualization 3-mm: retraction }\end{array}$ \\
\hline $\begin{array}{l}\text { Decarli et al } \\
(2009)^{65}\end{array}$ & Transvaginal & 2 & $3-\mathrm{mm} \times 2$ & Umbilicus & $\begin{array}{l}\text { Additional dissection port } \\
\text { using rigid instrumentation }\end{array}$ \\
\hline $\begin{array}{l}\text { Dallemagne et al } \\
(2009)^{44}\end{array}$ & Transgastric & $\mathrm{I}^{\mathrm{a}}$ & $5-\mathrm{mm}$ & Umbilicus & $\begin{array}{l}\text { Laparoscopic visualization, } \\
\text { retraction, primary port for } \\
\text { utilization of 5-mm endoclips }\end{array}$ \\
\hline $\begin{array}{l}\text { Asakuma et al } \\
(2009)^{45}\end{array}$ & Transgastric & $\mathrm{I}^{\mathrm{a}}$ & $5-\mathrm{mm}$ & Umbilicus & Laparoscopic visualization \\
\hline
\end{tabular}

Notes: "Hybrid" NOTES was created to overcome current technological barriers which exist in NOTES such as (I) gaining optic connection, (2) use of rigid instrumentation, (3) stable retraction, (4) visualization of the colpotomy or gastrotomy, and (5) safe closure of organ incision. "Hybrid" NOTES involves the placement of transabdominal needles or laparoscopic instruments to assist transluminal instrumentation.

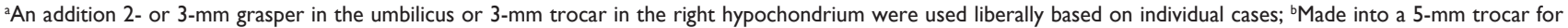
utilization of $5-\mathrm{mm}$ endoclips.

the distance from incision to the target organ is shorter and more direct via a transvaginal approach compared to a transgastric approach, and the ability to triangulate for optical correctness transvaginally makes dissection easier than via a transgastric method..$^{35}$

Zornig et al have the largest published experience with transvaginal "hybrid" NOTES cholecystectomies involving 68 patients. ${ }^{35}$ Initially, patients considered for NOTES must have had a BMI $<35$, no prior surgery and no symptoms of acute cholecystitis. As their experience grew, the investigators evolved their criteria to exclude only patients that had undergone prior pelvic surgery or radiation, had a BMI $>35$, a history of endometriosis or when severe adhesions were anticipated. All 68 procedures were successfully completed without the need for traditional laparoscopic conversion. There were no perioperative or immediate postoperative complications, however one patient $(1.47 \%)$ did present with a pelvic abscess three weeks postoperatively. All 68 patients were interviewed between 3 and 10 months postoperatively, and reported no procedural complaints. Forty-eight (70.6\%) of the patients reported having sexual intercourse within 6 weeks after the 


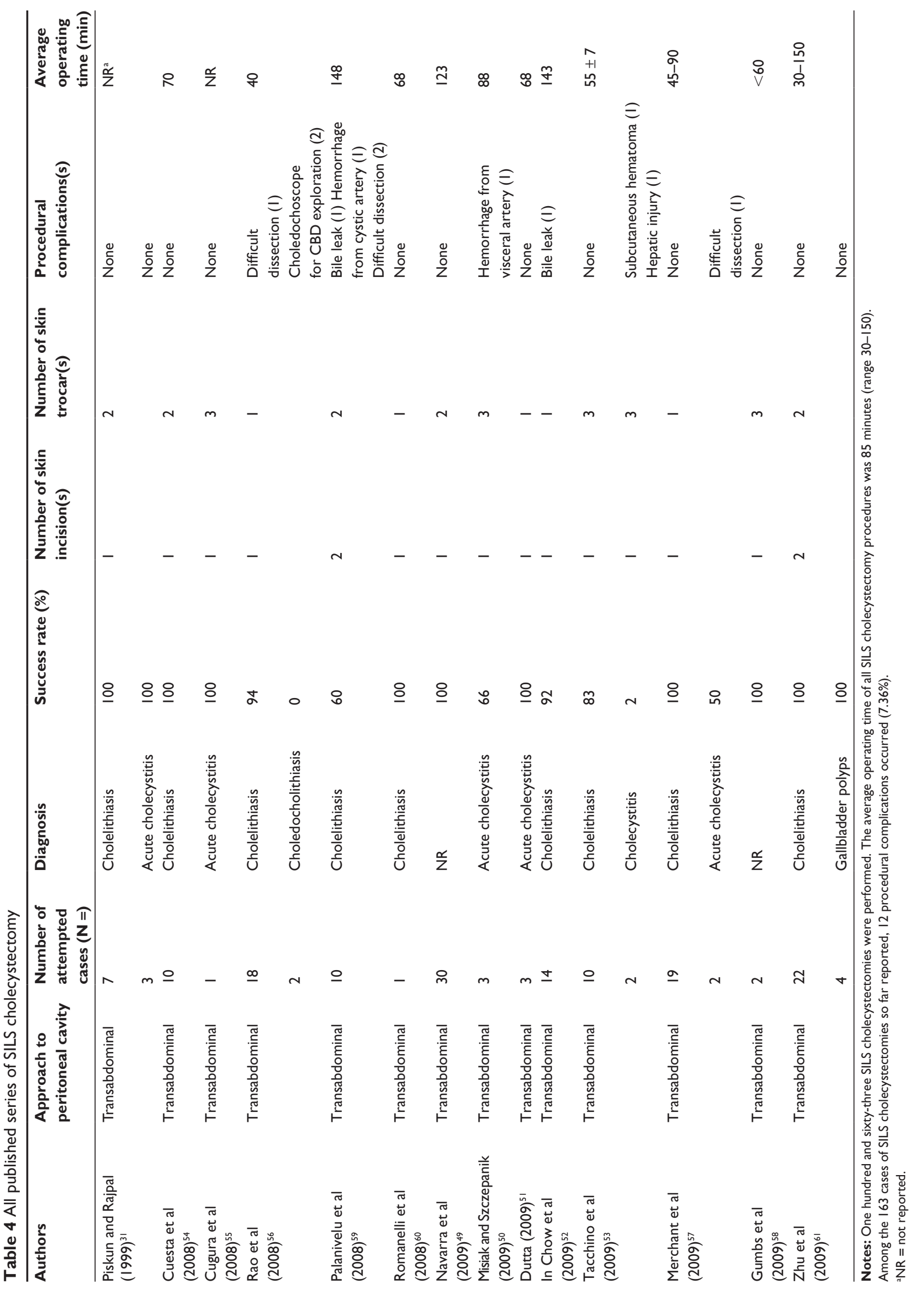


operation. The mean operating time for all 68 procedures was 51 minutes (range 30-100).

The surgical technique utilized by these authors involved placing the patient in the lithotomy position followed by perineal and abdominal prep with transvaginal iodopovidone. A 5-mm incision was made in the umbilicus through which a pneumoperitoneum was created and maintained. The patient was then placed in the steep Trendelenberg position to reduce the risk of accidental injury to the small bowel and to expose the pouch of Douglas. ${ }^{33,38}$ A 5-mm mandarin was inserted into the posterior fornix of the vagina under laparoscopic guidance via the $5-\mathrm{mm}$ umbilical port site and then replaced with a 5-mm extra-long dissector which was used for retraction of the gallbladder. Alongside this dissector, a 10-mm trocar was placed and an extra-long $45^{\circ}$ $10-\mathrm{mm}$ camera was inserted and utilized for the remainder of the operation. The dissection of the gallbladder including clipping and dividing the cystic duct and artery, and removal of the gallbladder from the underside of the liver with cautery was completed through the 5-mm umbilical port site. Once the gallbladder was fully mobilized, the umbilical dissector was exchanged with the original 5-mm camera and the specimen retrieval bag was placed through the $10-\mathrm{mm}$ vaginal trocar. The vaginal defects were closed with interrupted absorbable sutures in standard fashion.

Palanivelu et al have described a variation of this "hybrid" NOTES technique that was performed on 8 patients. ${ }^{43}$ Two patients (25\%) were converted to a traditional laparoscopic procedure due to either severe adhesions or a wide cystic duct that could not be completely occluded by endoclips. One patient (12.5\%) developed a bile leak due to a partially slipped endoclip. In the fourth week another patient (12.5\%) complained of dyspareunia whereby vaginal inflammation was observed. This patient subsequently recovered after treatment with antibiotics. The mean operative time for all eight procedures was 149 minutes (range 115-182). These authors placed a $3-\mathrm{mm}$ umbilical trocar through which a $3-\mathrm{mm}$ camera was inserted and used to help guide a double-channel endoscope from the vaginal incision to the gallbladder. The 3-mm camera was replaced with a 3-mm toothed grasper to help retract the gallbladder superiorly. A biopsy forceps was then inserted into the left working channel of the doublechannel endoscope to hold the infundibulum. In the right channel, a hot biopsy forceps with diathermy was used for dissection. The remainder of the operation was similar to that used by Zornig et al discussed above.

Gumbs et al was the first to report a "pure" NOTES cholecystectomy in June 2009. ${ }^{33}$ This report included four patients; the first three patients underwent a "hybrid" NOTES procedure similar to that described by Zornig et al while the fourth patient had a "pure" NOTES transvaginal cholecystectomy. Patients were excluded for consideration if they had acute cholecystitis, choledocholithiasis, gallstone pancreatitis, prior pelvic or abdominal surgery, a history of endometriosis, or pelvic inflammatory diseases. No complications were noted with this procedure; however the "pure" NOTES patient reported a higher pain score immediately postoperatively $(7 / 10)$ than the other 3 "hybrid".

NOTES patients (mean score $=4$ ). At 2- and 4-week follow-up all patients were pain-free, with no reported complications. This "pure" NOTES procedure took 185 minutes to complete.

The technique used for the "pure" NOTES procedure involved placing the patient in lithotomy and in a steep Trendelenberg position. The cervix was grasped and retracted upwards, and a $1-\mathrm{cm}$ incision was created in the posterior fornix with a bovie electrocautery knife followed by blunt dissection. A $15-\mathrm{mm}$ trocar was inserted followed by abdominal insufflation. A 12-mm double-channel gastroscope was then inserted and retroflexed to inspect surrounding areas for inadvertent injury. An adjacent laterally placed colpotomy was then made and a 5-mm trocar was inserted to permit a rigid curved 5-mm extra long reticulating retractor to be positioned in the right upper quadrant and used to retract the gallbladder. Skeletonization and dissection was completed through the working channels of the dual-chamber gastroscope with an endoscopic hook knife and a grasping biopsy forceps. The endoscopic clips were manually modified with 2 needle holders to straighten the tips, since there are no FDA-approved clips for ligation of the cystic duct and artery currently available. The gallbladder was dissected off the liver fossa with an endoscopic ball-tipped bovie electrocautery knife. After removal of the gallbladder, both colpotomies were closed in standard fashion.

Among the published NOTES cholecystectomy studies, 4 of 174 cases $(2.29 \%)$ were converted to traditional laparoscopy when severe adhesions or anatomic variants were encountered based upon the surgeons comfort level. ${ }^{26,35}$

\section{Transgastric approach to NOTES cholecystectomy}

Given the applicability to both genders, a transgastric approach to access the peritoneal cavity is the most promising route for NOTES. ${ }^{62}$ However, the technological, procedural and ethical issues surrounding transgastric approaches are 
numerous and only beginning to be addressed. ${ }^{7}$ To date, there have been only three case series of NOTES transgastric cholecystectomy reported, and all were "hybrid" in nature. The most pressing technical challenges for transgastric NOTES procedures include: (1) the lack of reliable flexible endoscopic platforms that can be used to gain safe transgastric entry, (2) concerns surrounding the risk of peritoneal contamination, (3) lack of current flexible instruments for retraction and dissection, and (4) development of a reliable method for gastric closure. ${ }^{26}$

Asakuma et al have reported the largest human transgastric "hybrid" NOTES cholecystectomy series, which involved 6 patients. ${ }^{45}$ All 6 patients underwent the procedure successfully. There were no laparoscopic or open conversions, and there were no postoperative complications. Mean operative time for all 6 transgastric cases was 138 minutes (range 120-180). The patients were positioned in the supine position and a $5-\mathrm{mm}$ trocar was placed through the umbilicus for insufflation. A 5-mm laparoscopic scope was placed through the umbilical trocar and a gastrotomy was made anteriorly in the mid-body of the stomach under direct visualization. Transcutaneous suspension of the falciform ligament with surgical tape was used to better expose the anatomy and an additional port was placed in the right hypochondrium if needed during dissection or as an additional port for retraction. All dissection, clipping, control of pneumoperitoneum, and closure of the gastric incision was performed via the umbilical trocar. The gallbladder was removed via the mouth.

Dallemagne et al have also reported on a modified "hybrid" transgastric NOTES technique in five patients. ${ }^{44}$ No peri-or postoperative complications were reported and the mean operative time was 150 minutes (range 120-180). This technique involved placing a 5-mm umbilical trocar, which was used for visualization of the gastrotomy, insufflation, monitoring of the pneumoperitoneum, and introduction of a 5-mm laparoscopic clip applier. An endoscopic monopolar needle-knife was used to create a 0.5 -cm gastrotomy anteriorly in the mid-body of the stomach. Expansion of the gastrotomy was accomplished by an 18-mm balloon dilator and allowed for delivery of a 12-mm gastroscope into the peritoneal cavity. Skeletonization of Calot's triangle was done using a flexible endoscopic blunt-tipped electrode. The cystic duct and artery were clipped using a laparoscopic clip applicator from the umbilical port. The gallbladder was separated from the liver fossa by use of blunt-tipped electrode, hook diathery, and traction achieved through the flexible endoscopic instruments. The gallbladder was pierced and drained of its contents under laparoscopic visualization, followed by its removal through the gastrotomy. Subsequent closure was completed using interrupted absorbable thread via a 2-mm laparoscope and a 3-mm needle holder inserted side by side into the $5-\mathrm{mm}$ umbilical port. Confirmation of a tight seal was made by observing the insufflation of air into the stomach.

\section{Transcolonic/transanal approach to NOTES cholecystectomy}

At present there have been no reported cases of a human transcolonic NOTES cholecystectomy. Similar to the transvaginal approach, the transcolonic approaches offers more practicality than a transgastric approach since the distance from the incision to the target region is much shorter and the abdominal cavity can be explored under conditions of optical correctness. ${ }^{26}$ That said, the curvature of the pelvis may pose a substantial obstacle when operating in the upper abdomen. Working in a skeleton model, Fiolka et al have developed a trocar with $60^{\circ}$ curvature to avoid impact with the sacral promontorium though this instrument has not been explored in vivo. ${ }^{26}$ Although Auyang et al have described the feasibility of obtaining the critical view of safety required for performing a cholecystectomy via a transcolonic route in a cadaveric porcine model, no human validation of this approach has occurred. ${ }^{2}$

Despite the noted potential advantages of a transcolonic NOTES approach, concerns surrounding peritoneal contamination and leak associated with a transcolonic approach have limited its applicability and development. ${ }^{63}$ Interestingly, some authors have suggested that a more distal rectal approach using a modified transanal endoscopic microsurgery (TEM) technique may obviate many current concerns surrounding transcolonic NOTES. A transrectal endoscopic retrorectal access (TERA) approach has been described by Ramamoorthy et al. ${ }^{14}$ Using a porcine model, the investigators made a posterior rectotomy directly above the dentate line, and found that a flexible endoscope could be placed in the retrorectal space allowing for safe balloon dilatation and access to the retrorectal plane. Entry to the peritoneal cavity was accomplished by utilization of a needle knife. No neighboring structures were damaged during this procedure. Although this rectal entry point shows promise, numerous concerns surrounding sterility, efficacy, and potential complications remain unknown. Without substantial research into colonic preparations, risk of luminal sterilization, incision site management, and development of "ideal" closure techniques, the future of transcolonic NOTES approach remains dubious in our estimation. 


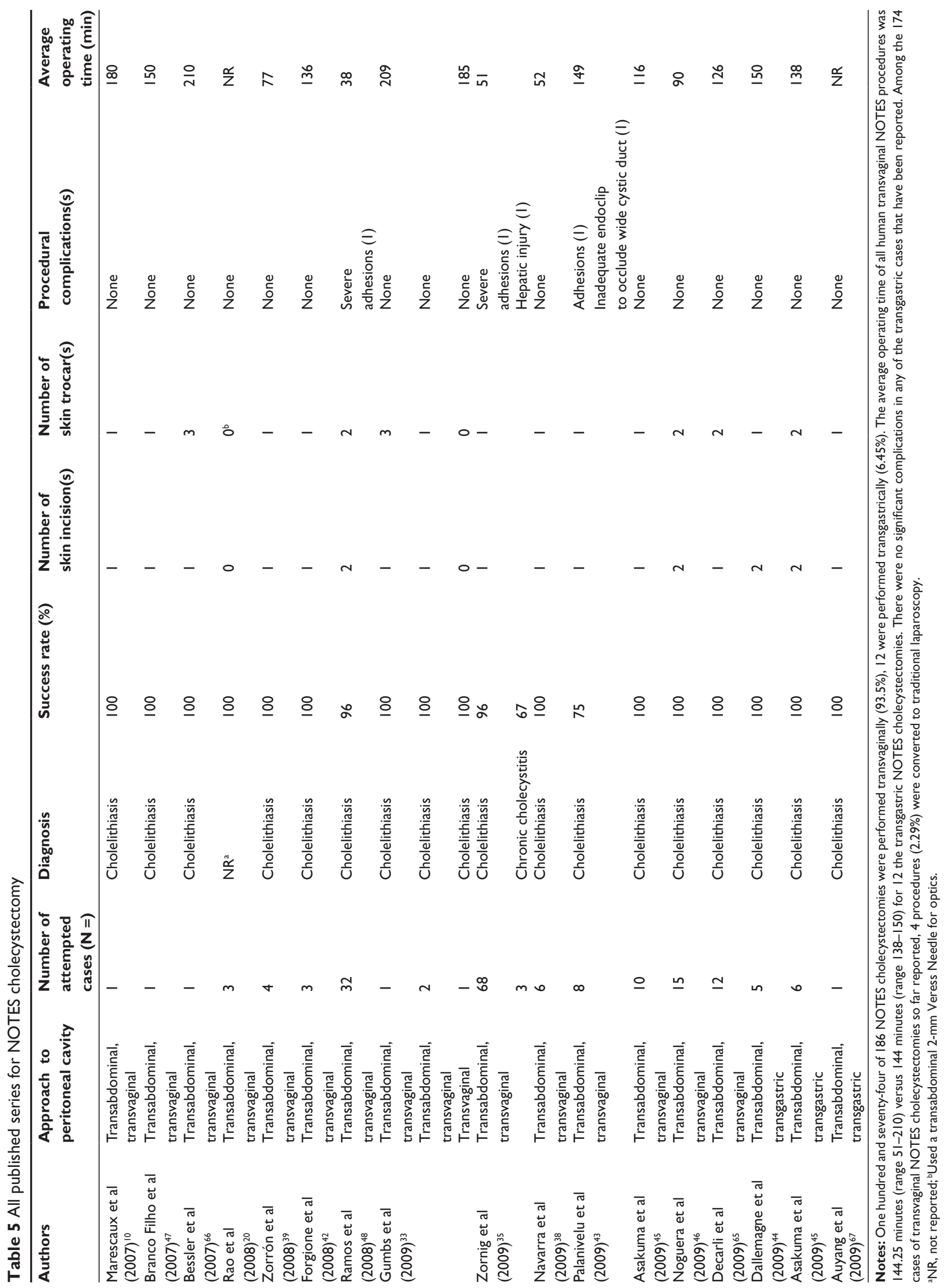




\section{Published human NOTES cholecystectomy trials: summary}

The results of all published human NOTES cholecystectomies are summarized in Table 5. Small sample size in most reports limits fruitful analysis of one technique versus another and limits comparison to traditional laparoscopic approaches. One hundred and seventy-four of 186 procedures were done transvaginally (93.5\%) and 12 were performed transgastrically (6.45\%). The average operating time for all human transvaginal NOTES procedures was 144.25 minutes (range 51-210) versus 144 minutes (range 138-150) for the 12 transgastric NOTES cholecystectomies. There were no significant complications in any of the transgastric cases reported. Among the 174 cases of transvaginal NOTES cholecystectomies, 4 procedures $(2.29 \%)$ were converted to traditional laparoscopy. Of note, the national average for conversion from laparoscopic to open cholecystectomy is $5 \%-10 \%{ }^{64}$ Whether this low conversion rate for NOTES remains static as the criteria for patient selection expands and more patients undergo NOTES for cholecystectomy is unclear, but seems unlikely.

\section{Conclusion}

Laparoscopy and minimally invasive surgery has flourished for two decades. The notion that "big surgeons make big scars" is now soundly rejected. Incisionless surgery, which once seemed fanciful, is now a reality limited only by technical advances and ethical dilemmas. Natural orifice transluminal endoscopic surgery or NOTES will ultimately be the next giant step in minimally invasive surgery. The idea of eliminating all skin incisions and operating transgastrically, transvaginally, or transcolonically has revolutionized the industrial side of minimally invasive surgery and is highly anticipated by surgeons. Perhaps most limiting to NOTES development at present is the simultaneous emergence of SILS approaches. SILS, like "hybrid" NOTES, offers improved cosmesis while using current instrumentation which is familiar to the practicing surgeon. It seems quite likely that until most, if not all, technological limitations of NOTES are overcome, and educations platforms are developed to allow surgeons to develop comfort and proficiency with current flexible endoscopic instruments, the adoption of NOTES in mainstream surgical practice is not imminent.

We remain convinced that the maturation of NOTES is an engineering issue that human thought and creativity will overcome. Until this happens, NOTES will (and should) be performed by only a select group of surgical innovators who possess the scientific curiosity, and the necessary endoscopic, laparoscopic and open surgical skills to help mature NOTES and protect patients. Whether NOTES represents a "leap" or a "step" forward is yet to be determined, and whether "hybrid" or "pure" forms ultimately emerge is unclear. "Hybrid" NOTES while sounding more attractive, may simply be SILS in a prettier box. Appropriate patient selection for NOTES remains critical to patient safety, and in the end NOTES will likely not be broadly applicable to all patients.

\section{Disclosure}

No conflicts of interest were declared in relation to this paper.

\section{References}

1. Bittner R. The standard of laparoscopic cholecystecomy. Langenbecks Arch Surg. 2004;389:157-163.

2. Auyang ED, Hungness ES, Vaziri K, Martin JA. Natural orifice transluminal endoscopic surgery (NOTES): dissection for the critical view of safety during transcolonic cholecystectomy. Surg Endosc. 2009; 23:1117-1118.

3. Pham BV, Morgan K, Romagnuolo J, et al. Pilot comparison of adhesion formation following colonic perforation and repair in a pig model using a transgastric, laparoscopic, or open surgical technique. Endoscopy. 2008; 40(8):664-669.

4. Lau WY, Leow CK, Li AK. History of endoscopic and laparoscopic surgery. World J Surg. 1997;21:444-453.

5. Mühe E. Die erst: cholecystecktomie durch das laparoskop (The first laparoscopic cholecystectomy). Langenbecks Arch Surg. 1986;369:804.

6. Kaiser AM, Corman ML. History of laparoscopy. Surg Onco Clin NAm. 2001;10:483-492.

7. Chamberlain RS, Sakpal SV. A comprehensive review of single-incision laparoscopic surgery (SILS) and natural orifice transluminal endoscopic surgery (NOTES) techniques for cholecystectomy. J Gastrointest Surg. 2009;13:1733-1740.

8. Kalloo AN, Singh VK, Jagannath SB, et al. Flexible transgastric peritoneoscopy: a novel approach to diagnostic and therapeutic interventions in the peritoneal cavity. Gastrointest Endos. 2004;60:114-117.

9. Reddy N, Rao P. Per oral transgastric endoscopic appendectomy in human. Abstract presented at 45th Annual Conference of the Society of Gastrointestinal Endoscopy of India; 2004 Feb 28-29; Jaipur, India.

10. Marescaux J, Dallemagne B, Perretta S, WattiezA, Mutter D, Coumaros D. Surgery without scars: report of transluminal cholecystectomy in a human being. Arch Surg. 2007;142(9):823-827.

11. Rattner D, Kalloo A. ASGE/SAGES working group on natural orifice transluminal endoscopic surgery. Oct 2005. Surg Endosc. 2006; 20:329-333.

12. Lomanto D, Chua HC, Myat MM, So J, Shabbir A, Ho L. Microbiological contamination during transgastric and transvaginal endoscopic techniques. J Laparoendo Adv Surg Techn. 2009;19(4):465-469.

13. Cahill RA. Natural orifice transluminal endoscopic surgery- here and now. The Surgeon. 2010;8:44-50.

14. Ramammoorthy SL, Fischer LJ, Jacobsen G, et al. Transrectal endoscopic retrorectal access: a novel NOTES approach to the peritoneal cavity. J Lapendo Adv Surg Tech. 2009;19(5):603-606.

15. Ryou M, Thompson CC. Transmural gastric closure and NOTES - How far have we come? Endoscopy. 2009;41:558-559.

16. Voermans RP, Worm AM, van Berge Henegouwen MI, et al. In vitro comparison and evaluation of seven gastric closure modalities for natural orifice transluminal endoscopic surgery (NOTES). Endoscopy. 2008; 40:595-601. 
17. Narula VK, Happel LC, Volt K, et al. Transgastric endoscopic peritoneoscopy does not require decontamination of the stomach in humans. Surg Endosc. 2009;23:1331-1336.

18. Cindolo L, Gidaro S, Schips L. Urological applications of N.O.T.E.S. Surg Onc. 2009;18(2):153-156.

19. Rolanda C, Lima E, Pego JM, et al. Third-generation cholecystectomy by natural orifices: transgastric and transvesical combined approach (with video). Gastrointest Endosc. 2007;65(1):111-117.

20. Roa GV, Reddy DN, Banerjee R. NOTES: human experience Gastrointest Endoscopy Clin N Am. 2008;18:361-370.

21. Buess G, Mentges B, Manncke K, et al. Minimal invasive surgery in the local treatment of rectal cancer. Int J Colorectal Dis. 1991;6:77-81.

22. McGee MF, Rosen MJ, Marks J, et al. A reliable method for monitoring intraabdominal pressure during natural orifice transluminal endoscopic surgery. Surg Endosc. 2007;21:672-676.

23. Merielles O, Kantsevoy SV, Kalloo AN, et al. Comparison of intraabdominal pressures using the gastroscope and laparscope for transgastric surgery. Surg Endosc. 2007;21:998-1001.

24. Von Delius S, Huber W, Feussner H, et al. Effect of pneumoperitoneum on hemodynamics and inspiratory pressures during natural orifice Transluminal endoscopic surgery (NOTES): an experimental, controlled study in an acute porcine model. Endoscopy. 2007;39:854-861.

25. Sugimoto M, Yasuda $H$, Koda K, et al. Evaluation for transvaginal and transgastric NOTES cholecystectomy in humans and animal natural orifice translumenal endoscopic surgery. J Hepatobiliary Pancreat Surg. 2009;16:255-260.

26. Fiolka A, Can S, Schneider A, Wilhelm D, Feussner H. Instrumentation and surgical technique for an innovative safe sigmoid approach for NOTES. Min Inv Ther. 2008;17(6):336-340.

27. Swanstromm LL, Kozarek R, Pasricha PJ, et al. Development of a new access device for transgastric surgery. Gastrointest Surg. 2005; 9:1129-1136.

28. Sumiyama K, Gostout CJ. Techniques for transgastric access to the peritoneal cavity. Gastrointest Endosc Clin N Am. 2008;18:235-244.

29. Ryou M, Thompson CC. Magnetic retraction in natural-orifice transluminal endoscopic surgery (NOTES): addressing the problem of traction and countertraction. Endoscopy. 2009;41:143-148.

30. Spaun GO, Zheng B, Mertinec DV, Cassera MA, Dunst CM, Swanstrom LL. Bimanual coordination in NOTES: comparing conventional dual-channel endoscope, the R-scope and a novel direct drive system. Gastrointest Endosc. 2009;69(6):e39-e45.

31. Piskun G, Rajpal S. Transumbilical laparoscopic cholecystectomy utilizes no incisions outside the umbilicus. J Laparoendosc Adv Surg Tech A. 1999;9:361-364.

32. Karimyan V, Sodergren M, Clark J, Yang GZ, Darzi A. Navigation systems and platforms in natural orifice translumenal endoscopic surgery (NOTES). Intl J Surg. 2009;7:297-304.

33. Gumbs AA, Fowler D, Milone L, et al. Transvaginal natural orifice translumenal endoscopic surgery cholecystectomy: early evolution of the technique. Ann Surg. 2009;249(6):908-912.

34. Al-Akash M, Boyle E, Tanner WA. Training on N.O.T.E.S.: From history we learn. Surg Oncol. 2009;18:111-119.

35. Zornig C, Mofid H, Siemssen L, et al. Transvaginal NOTES hybrid cholecystectomy: feasibility results in 68 cases with mid-term follow-up. Endoscopy. 2009;41:391-394.

36. Onders RP, McGee MF, Marks J, et al. Natural orifice transluminal endoscopic surgery (NOTES) as a diagnostic tool in the intensive care unit. Surg Endosc. 2007;21:681-683.

37. Varadarajulu S, Tamhane A, Drelichman ER. Patient perception of natural orifice transluminal endoscopic surgery as a technique for cholecystectomy. Gastrointest Endosc. 2008;67:854-860.

38. Navarra G, Rando L, La Malfa G, Bartolotta G, Pracanica G. Hybrid transvaginal cholecystectomy: a novel approach. Am J Surg. 2009;197: e69-e72.

39. Zorrón R, Maggioni LC, Pombo L, Oliveira AL, Carvalho GL, Filgueiras M. NOTES transvaginal cholecystectomy: preliminary clinical application. Surg Endosc. 2008;22:542-547.
40. Zorrón R, Filgueiras M, Maggioni LC, Pombo L, Carvalho GL, Oliveira AL. NOTES transvaginal cholecystectomy: report of the first case. Surg Innov. 2007;14(4):279-283.

41. Zornig C, Emmermann A, von Waldenfels HA, Mofid H. Laparoscopic cholecystectomy without visible scar: combined transvaginal and transumbilical approach. Endoscopy. 2007;39:913-915.

42. Forgione A, Maggioni D, Sansonna F, et al. Transvaginal endoscopic cholecystectomy in human beings: preliminary results. $J$ Laparoendosc Adv Surg Tech A. 2008;18:345-351.

43. Palanivelu C, Rajan PS, Rangarajan M, et al. NOTES: transvaginal endoscopic cholecystectomy in humans- preliminary report of a case series. Am J Gastreoenterol. 2009;104:843-847.

44. Dallemagne B, Perretta S, Allemann P, Asakuma M, Marescaux J. Transgastric hybrid cholecystectomy. Br J Surg. 2009;96: 1162-1166.

45. Asakuma M, Perretta S, Allemann P, et al. Challenges and lessons learned from NOTES cholecystectomy initial experience: a step wise approach from the laboratory to clinical application. $J$ Heaptobiliary Pancreat Surg. 2009;16:249-254.

46. Noguera J, Dolz C, Cuadrado A, Olea J, Vilella A, Morales R. Hybrid transvaginal cholecystectomy, NOTES, and minilaparoscopy: analysis of a prospective clinical series. Surg Endosc. 2009;23:876-881.

47. Branco Filho AJ, Noda RW, Kondo W, Kawahara N, Rangel M, Branco AW. Initial experience with hybrid transvaginal cholecystectomy. GI Endosc. 2007;66(6):1245-1248.

48. Ramos AC, Murakami A, Neto MG, et al. NOTES transvaginal videoassisted cholecystectomy: first series. Endoscopy. 2008;40:572-575.

49. Navarra G, Pozza E, Occhionorelli S, Carcoforo P, Donini I. One-wound laparoscopic cholecystectomy. Br J Surg. 1997;84:695.

50. Misiak A, Szczepanik AB. Laparoscopic cholecystectomy with single incision laparoscopic surgery. Polski Merkuriusz Lekarski. 2009;27(161):372-374.

51. Dutta S. Early experience with single incision laparoscopic surgery: eliminating the scar from abdominal operations. J Ped Surg. 2009;44(9): 1741-1745.

52. Chow A, Purkayastha S, Paraskeva P. Appendicectomy and cholecystectomy using single-incision laparoscopic surgery (SILS): the first UK experience. Surg Innov. 2009;16(3):211-217.

53. Tacchino R, Greco F, Matera D. Single-incision laparoscopic cholecystectomy: surgery without a visible scar. Surg Endosc. 2009;23(4): 896-899.

54. Cuesta MA, Berends F, Veenhof AA. The "invisible cholecystectomy": A transumbilical laparoscopic operation without a scar. Surg Endosc. 2008;22:1211-1213.

55. Cugura JF, Jankovic J, Kulis T, Kirac I, Beslin MB. Single incision laparoscopic surgery (SILS) cholecystectomy: where are we? Acta Clinica Croatia. 2008;47(4):245-248.

56. Rao PP, Bhagwat SM, Rane A, Rao PP. The feasibility of single port laparoscopic cholecystectomy: a pilot study of 20 cases. HPB Oxf. 2008; 10 : 336-340.

57. Merchant AM, Cook MW, White BC, Davis SS, Sweeney JF, Lin E. Transumbilical gelport access technique for performing single incision laparoscopic surgery (SILS). J Gastrointest Surg. 2009;13: $159-162$.

58. Gumbs AA, Milone L, Sinha P, Bessler M. Totally transumbilical laparoscopic cholecystectomy. J Gastrointest Surg. 2009;13:533-534.

59. Palanivelu C, Rajan PS, Rangarajan M, Parthasarathi R, Senthilnathan P, Praveenraj P. Transumbilical flexible endoscopic cholecystectomy in humans: first feasibility study using a hybrid technique. Endoscopy. 2008; 40:428-431.

60. Romanelli JR, Mark L, Omotosho PA. Single port laparoscopic cholecystectomy with the TriPort system: a case report. Surg Innov. 2008; $15: 223-228$

61. Zhu JF, Hu H, Ma YZ, Li F. Transumbilical endoscopic surgery: a preliminary clinical report. Surg Endosc. 2009;23:813-817.

62. Thele F, Zygmunt M, Glitsch A, et al. How do gynecologists feel about transvaginal NOTES surgery? Endoscopy. 2008;40:576-580. 
63. Fong DG, Pai RD, Thompson CC. Transcolonic endoscopic abdominal exploration: a NOTES survival study in a porcine model. Gastrointest Endosc. 2007;65:312-318.

64. Livingston E, Rege RV. A nationwide study of conversion from laparoscopic to open cholecystectomy. Am J Surg. 2004;188(3): 205-211.

65. Decarli LA, Zorron R, Branco A, et al. New hybrid approach for NOTES transvaginal cholecystectomy: preliminary clinical experience. Surg Innov. 2009;16(2):181-186.
66. Bessler M, Stevens PD, Milone L, Parikh M, Fowler D. Transvaginal laparoscopically assisted endoscopic cholecystectomy: a hybrid approach to natural orifice surgery. Gastrointest Endosc. 2007;66:1243-1245.

67. Auyang E, Hungness ES, Vaziri K, Martin JA, Soper NJ. Human NOTES cholecystectomy: transgastric hybrid technique. J Gastrointest Surg. 2009; 13:1149-1150.

\section{Publish your work in this journal}

Open Access Surgery is an international, peer-reviewed, open access journal that focuses on all aspects of surgical procedures and interventions. Patient care around the peri-operative period and patient outcomes post surgery are key topics. All grades of surgery from minor cosmetic interventions to major surgical procedures are covered. Novel techniques

Submit your manuscript here: http://www.dovepress.com/open-access-surgery-journal

\section{Dovepress}

and the utilization of new instruments and materials, including implants and prostheses that optimize outcomes constitute major areas of interest. The manuscript management system is completely online and includes a very quick and fair peer-review system. Visit http://www.dovepress.com/ testimonials.php to read real quotes from published authors. 